\title{
Article \\ Using Human Biomonitoring Data to Support Risk Assessment of Cosmetic Ingredients-A Case Study of Benzophenone-3
}

\author{
Christophe Rousselle ${ }^{1}$, Matthieu Meslin ${ }^{2, *(\mathbb{D})}$, Tamar Berman ${ }^{3}$, Marjolijn Woutersen ${ }^{4}$, Wieneke Bil ${ }^{4}$, \\ Jenna Wildeman ${ }^{4}$ and Qasim Chaudhry ${ }^{5}$
}

1 European and International Affairs Department, Anses, 94701 Maisons-Alfort, France; christophe.rousselle@anses.fr

2 Risk Assessment Department, Anses, 14 rue Pierre et Marie Curie, 94701 Maisons-Alfort, France

3 Ministry of Health, Jerusalem 9101002, Israel; tamar.berman@moh.gov.il

4 RIVM National Institute for Public Health and the Environment, 3721 MA Bilthoven, The Netherlands; marjolijn.woutersen@rivm.nl (M.W.); wieneke.bil@rivm.nl (W.B.); jennawildeman@outlook.com (J.W.)

5 Department of Clinical Sciences and Nutrition, University of Chester, Parkgate Road, Chester CH1 4BJ, UK; q.chaudhry@chester.ac.uk

* Correspondence: matthieu.meslin@anses.fr

check for updates

Citation: Rousselle, C.; Meslin, M.; Berman, T.; Woutersen, M.; Bil, W.; Wildeman, J.; Chaudhry, Q. Using Human Biomonitoring Data to Support Risk Assessment of Cosmetic Ingredients-A Case Study of Benzophenone-3. Toxics 2022, 10, 96. https://doi.org/10.3390/ toxics10020096

Academic Editor: Giovanna Tranfo

Received: 10 January 2022

Accepted: 16 February 2022

Published: 19 February 2022

Publisher's Note: MDPI stays neutral with regard to jurisdictional claims in published maps and institutional affiliations.

Copyright: (c) 2022 by the authors. Licensee MDPI, Basel, Switzerland. This article is an open access article distributed under the terms and conditions of the Creative Commons Attribution (CC BY) license (https:// creativecommons.org/licenses/by/ $4.0 /)$.

\begin{abstract}
Safety assessment of UV filters for human health by the Scientific Committee on Consumer Safety (SCCS) is based on the estimation of internal dose following external (skin) application of cosmetic products, and comparison with a toxicological reference value after conversion to internal dose. Data from human biomonitoring (HBM) could be very useful in this regard, because it is based on the measurement of real-life internal exposure of the human population to a chemical. UV filters were included in the priority list of compounds to be addressed under the European Human Biomonitoring Initiative (HBM4EU), and risk assessment of benzophenone-3 (BP-3) was carried out based on HBM data. Using BP-3 as an example, this study investigated the benefits and limitations of the use of external versus internal exposure data to explore the usefulness of HBM to support the risk assessment of cosmetic ingredients. The results show that both approaches did indicate a risk to human health under certain levels of exposure. They also highlight the need for more robust exposure data on BP-3 and other cosmetic ingredients, and a standardized framework for incorporating HBM data in the risk assessment of cosmetic products.
\end{abstract}

Keywords: human biomonitoring; UV filters; benzophenone-3; HBM4EU; risk assessment; RCR; margin of safety

\section{Introduction}

UV filters are used in sunscreen and other cosmetic products to protect the skin by absorbing or reflecting potentially harmful UVA and UVB rays.

UV filters in sunscreens are regulated in Europe in the Cosmetic Product Regulation (CPR), which provides a broad regulatory framework for restricting chemicals with potential risks to human health. The CPR does not include specific restrictions on endocrine disrupting (ED) chemicals, however, and as there was concern for these substances the European Commission started a review of cosmetic ingredients with ED properties in 2018 [1]. As a result of the review, the Commission established a "short" list of potential EDs in cosmetics, which included benzophenone-3 (BP-3). Subsequently, the Scientific Committee on Consumer Safety (SCCS), which provides opinions on health and safety risks (chemical, biological, mechanical and other physical risks) of non-food consumer products (cosmetics, personal-care products, toys, textiles, etc.), was mandated by the Commission to carry out a safety assessment of BP-3 in view of concerns related to potential ED properties [2].

The SCCS approach to assessing the safety of cosmetic ingredients to the consumers is based on first estimating the external dose that is in contact with the skin, followed by 
estimation of the internal dose that will be systemically available after crossing the skin. The internal exposure dose is then compared to a reference value that is either derived from human or experimental data. This toxicological reference value (TRV) is used by the SCCS to calculate a margin of safety (MoS) [3]. In this context, human biomonitoring (HBM) can provide a very useful tool because it provides real-life internal exposure of the human population to a given chemical in terms of measured concentrations in human samples, such as blood and urine. There has been an increasing use of HBM for exposure assessment in the European risk assessment schemes in recent years, although the level of use is still limited. Based on a survey of different risk assessment frameworks in the EU, less than $30 \%$ of respondents replied that HBM is regularly applied in the regulatory domain in their country [4]. The use of HBM in risk assessments has also been uneven across different frameworks; for example, compared to pesticides, biocides, and heavy metals, the use of HBM data has been scarce in cosmetics safety assessments.

The European Human Biomonitoring Initiative (HBM4EU), running from 2017 to 2022, has established a European-Union-wide human biomonitoring program to generate knowledge on human internal exposure to chemical pollutants and their potential health impacts in Europe, to support policy makers' efforts to regulate chemical safety and improve public health in Europe [5]. One of the goals of HBM4EU is to support policy making by providing evidence of the actual exposure of EU citizens to chemical substances and mixtures to inform risk assessment. The current study was aimed at exploring the potential usefulness of HBM data for supporting the risk assessment of cosmetic ingredients, using BP-3 as an example.

\section{Methodological Approach}

\subsection{Risk Assessment Based on External Approach}

The approach used by the SCCS to assess the safety of cosmetic ingredients, for which an opinion is required, is based on the calculation of a margin of safety. The method followed by the committee is described in detail in the Note of Guidance [3].

\subsubsection{Margin of Safety Calculation}

In the risk characterization of a cosmetic ingredient, the main focus is on systemic effects, with separate consideration of any local effects. The MoS is generally calculated based on oral toxicity studies unless robust dermal toxicity data are available. For this, a toxicological point of departure (PoD), derived from oral studies in test animals, has historically been used in the following Equation (1):

$$
\mathrm{MoS}=\text { PoDsys } / \text { SED }
$$

where PoDsys (systemic PoD in $\mathrm{mg} / \mathrm{kg}$ bw/day) is the potency descriptor, preferably a benchmark dose (BMD) or alternatively a NOAEL (no observed adverse effect level) or LOAEL (lowest observed adverse effect level) from a repeated-dose toxicity study. As these values are often based on oral studies, they are corrected for the oral bioavailability of the compounds to derive the PoDsys. It is considered that not more than $50 \%$ of an orally administered dose is systemically available. Thus, in the absence of data, $50 \%$ of the administered dose is used as the default oral absorption value for a cosmetic ingredient and the PoDsys is derived from the PoD by dividing by 2. SED (systemic exposure dose in $\mathrm{mg} / \mathrm{kg} \mathrm{bw} /$ day) is a dose descriptor for the systemic exposure to the substance calculated as the amount of the substance systemically absorbed from cosmetic products.

Taking into account the extrapolation uncertainties corresponding to differences in toxicokinetics and toxicodynamics between experimental animals and humans (a factor of 10), and toxicological sensitivity differences within the human population due to differences in biology, age, sex, health status, etc. (a factor of 10), an MoS equal to or higher than 100 $(10 \times 10)$ is considered an adequate indicator of safety of the substance to human health. Other default assessment factors (AFs) may also be applied to take into account for example lack of data, but this was not applicable in this case [6]. 


\subsubsection{Hazard Assessment: Selection of an External Critical Dose}

In this study, the selection of the critical effect, the key study, and the external critical dose of BP-3, was carried out following the methodology described in the SCCS Notes of Guidance [3]. Cosmetic safety assessments have historically used NOAEL as the toxicological PoD. The NOAEL is the highest dose or exposure level where no (adverse) treatment-related effects were observed. The external critical dose of the assessed ingredient (e.g., BP-3) is usually derived from a repeated-dose toxicity study that indicates an adverse effect, such as a chronic or a reproductive toxicity study [3].

The study selection process considered the assessment of all toxicological effect(s), their dose-response relationships, and possible threshold(s). Moreover, all periods of exposure including the most sensitive ones were considered, and in particular, exposure during pregnancy. The studies in which pregnant animals were exposed were therefore more thoroughly assessed.

\subsubsection{Exposure Dose (SED) Calculation Based on Skin Application}

The human exposure to BP-3 can arise from cosmetic products as well as from other sources. BP-3 is currently regulated in sunscreens as a UV-filter with a maximum allowed concentration of $6 \%$ and in other cosmetic products with a concentration limit of $0.5 \%$. BP-3 is also used in other product groups, such as coating products, plasters, modeling clay and finger paints, machine washing liquids/detergents, automotive care products, paints and coating or adhesives, and fragrances and air fresheners [7]. Exposure to BP-3 used as a UV-filter in cosmetic products was calculated based on the exposure scenarios by multiplying the concentration of BP-3 at the maximum approved concentrations $(6 \%$ in sunscreen products and $0.5 \%$ in other cosmetic products). The external dermal exposure $\left(E_{\text {dermal }}\right)$ per day of BP-3 was then calculated taking into account the retention factor, concentration of BP-3 in the product, and amount of product applied daily, according to Equation (2):

$$
\mathrm{E}_{\text {dermal BP-3 }}=\mathrm{C}_{\mathrm{BP}-3} \times \mathrm{q}_{\mathrm{x}} \times \mathrm{f}_{\text {ret }}
$$

where $\mathrm{E}_{\text {dermal BP-3 }}(\mathrm{mg} /$ day): external exposure to BP-3 available for dermal uptake from a product category.

$\mathrm{C}_{\mathrm{BP}-3}(\mathrm{mg} / \mathrm{g})$ : concentration of BP-3 in the product category.

$\mathrm{q}_{\mathrm{x}}$ (g/day): amount of product category that is applied per day.

$\mathrm{f}_{\text {ret }}$ : retention factor specific to the product category; for leave-on cosmetics, including UV-cream, a fraction of $1(100 \%)$ is used, while for rinse-off cosmetics (e.g., shower gel, shampoo, etc.) a smaller fraction is used that depends on the type and use of the respective product.

Next, external dermal exposure was multiplied by skin penetration value to calculate the systemic exposure dose (SED). Skin penetration can be determined from in vivo or in vitro studies. The approach preferred by the SCCS is based on selecting in vitro studies using published criteria [8].

\subsection{Risk Assessment Based on Internal Approach}

In HBM the internal human exposure is determined by measuring a substance itself or its metabolites in biological samples, usually blood or urine, in a human study population. The risk is calculated by comparing this internal exposure to a human biomonitoring guidance value (HBM-GV). As the HBM-GV used for BP-3 has no legal status, and has not been derived as an official HBM4EU guidance value, it should be considered a provisional HBM-GV in the context of this study.

\subsubsection{Risk Characterization Based on HBM Data}

Following the internal approach, the risk characterization ratio (RCR) for BP-3 is calculated by comparing the typical case (TC) exposure estimate and the reasonable worst- 
case (RWC) exposure estimate in each study to the provisional HBM-GV, as described in Equations (3) and (4):

$$
\begin{gathered}
\mathrm{RCR}(\mathrm{TC})=\frac{\text { Range of median values }}{\text { provisional HBM }-\mathrm{GV}} \\
\mathrm{RCR}(\mathrm{RWC})=\frac{\text { Range of P95 values }}{\text { provisional HBM }-\mathrm{GV}}
\end{gathered}
$$

RCRs greater than 1 imply that the population assessed is (partly) exposed above the derived guidance value, and is thus potentially at risk of adverse effects from the chemical (e.g., BP-3).

\subsubsection{Provisional HBM-GV Derivation Using the Urinary Mass Balance Approach}

A provisional HBM-GV is based on a PoD, reflecting the critical endpoint identified in hazard characterization and used as a reference point for the urinary concentration levels measured. For the derivation of the provisional HBM-GV, the urinary mass balance approach is applied [9]. This method can be applied to substances that are primarily eliminated through urinary excretion, and for which regular repeated exposure is likely. For such substances, the approach assumes a balance between the substance intake and the substance excretion, reaching a steady-state in the urine matrix. Under this assumption, the urinary excretion rate is a constant fraction of the intake rate [10].

Using this method, the critical dose from an experimental animal study (animal PoD) was transformed into a human biomarker concentration consistent with that dose (provisional HBM-GV) based on the urinary mass balance assumption. The animal PoD was first extrapolated to a human equivalent (external) TRV with application of assessment factors to account for extrapolation uncertainties (see Equation (5)). As for the external approach described above, the factors for allometric scaling and remaining toxicokinetic differences were applied to account for the differences in toxicokinetics and toxicodynamics between experimental animals and humans. An intraspecies factor was also applied [6].

$$
\mathrm{TRV}=\frac{\text { Animal PoD }}{\text { Overall AF }}
$$

Next, a provisional HBM-GV was calculated from the TRV, using Equation (6), with parameters defined as follows:

- provisional HBM-GV: the human biomonitoring guidance value below which no adverse health effect should be expected, expressed as the substance concentration per gram creatinine ( $\mu \mathrm{g} / \mathrm{g}$ creatinine).

- TRV: toxicological reference value, the external human value corresponding to the animal PoD (mg/kg bw/day).

- Fue: substance-specific steady-state fraction of urinary excretion, the daily proportion of the intake dose excreted in urine.

- $\quad$ Creatinine excretion rate adjusted to BW: typical $24 \mathrm{~h}$ creatinine excreted, adjusted to default human bodyweight ( $\mathrm{g} / \mathrm{kg}$ bw/day), to compensate for differences in the volume of urine excreted.

$$
\text { provisional } \mathrm{HBM}-\mathrm{GV}=\frac{\mathrm{TRV} * \text { Fue }(\text { substance) }}{\text { Creatinine excretion rate adjusted to } \mathrm{BW}}
$$

\subsubsection{Systemic Exposure Dose Calculation Based on an Internal Approach}

A systematic review was performed to assess the levels of BP-3 exposure in the European general population using the search engine Embase.com (Amsterdam: Elsevier) to gather all available human biomonitoring studies. Articles were qualitatively considered for compiling the BP-UV filter exposure database with European exposure data. Selected articles were then quantitatively screened for meta-analysis of BP-3 exposure in the Eu- 
ropean general population. As older studies are considered less relevant for the current situation, only data after 2006 were included. The analysis included only European studies that applied enzymatic deconjugation of the samples and storage at $<4{ }^{\circ} \mathrm{C}$, as these are generally considered critical aspects of sample treatment to obtain reliable and comparable results [11].

After study selection based on the criteria, the overlapping cohorts amongst the multiple included articles were removed. In filtering out the overlapping cohorts, studies with larger sample sizes, more detailed data reporting, and analysis of multiple benzophenones, were prioritized. The risk of bias of the individual studies was evaluated and studies were excluded from the meta-analysis in case of a considerable risk of bias.

The summary statistics were calculated for a typical case exposure and a reasonable worst case exposure. The typical case exposure is described by the median and range (min-max) of median values from the included studies and the reasonable worst-case by the median and range (min-max) of P95 values. Descriptive statistics that were below LOD or LOQ were replaced with the corresponding LOD or LOQ value, conforming to the statistical analysis of the CONTAM panel [12]. All statistical analyses were performed in Excel.

\section{Results}

3.1. Risk Assessment Based on External Approach

\subsubsection{Selection of External Critical Dose}

Previous safety assessments of BP-3 by the European Scientific Committees [13-15] concluded that BP-3 can be safely used as a UV-filter up to $6 \%$ in cosmetic sunscreen products and up to $0.5 \%$ in all types of cosmetic products although it has the potential for contact allergy and photoallergy. The recent assessment by the SCCS [2] considered previous evaluations, as well as new information, with a particular focus on the potential ED properties of BP-3.

The information available under REACH has categorized BP-3 as non-sensitizing, non-irritant to eyes and skin, and suggests no acute adverse effects [7]. Both human epidemiological and animal experimental studies have associated BP-3 exposure to reproductive and developmental toxicity [2]. Within the CLP regulation (EC No. 1272/2008) (classification, labeling, and packaging) [16], BP-3 is not considered to meet the criteria for reproductive toxicity classification [7]. Systematic reviews have highlighted a varying relationship between BP-3 exposure and estrogenic, androgenic, and antiandrogenic activities frequently reported in vivo and in vitro $[17,18]$. However, the clinical relevance of the endocrine effects in these studies is not always clear, and uncertainty remains over when the observed endocrine effects can be interpreted as adverse. This led the SCCS to conclude that the currently available evidence on ED properties of BP-3-including in silico modeling and in vitro and in vivo studies - was inconclusive and at best equivocal when considered individually or taken together. Therefore, the SCCS did not derive a new PoD on ED properties to use in the risk assessment.

To calculate the MoS, the SCCS used the lowest NOAEL values $(67.9 \mathrm{mg} / \mathrm{kg}$ bw $/ \mathrm{d})$ derived from a study by Nakamura et al. [19]. The Nakamura et al. (2015) study [19] determined the effects of maternal and lactational exposure to BP-3 (between 0-3448 mg/kg/day) on the development and reproductive organs of the offspring of time-mated female rats. There were no significant differences on the reproductive/ pregnancy parameters or sex ratio of the offspring between the control and BP-3-dosed groups. In the highest dose groups, there was a significant reduction in the normalized anogenital distance on post-natal day (PND) 23 in male pups, a decrease in serum ALT (albumin transferase) and a significant increase in cholesterol levels in both female and male offspring at PND 23. Body, ovarian and uterine weights were significantly reduced. Relative liver-to-body-weight ratios were also significantly increased and paired kidney weights were lower.

In addition, in the highest dose group, seminiferous tubules contained few or no spermatocytes compared to the control group. The SCCS considered $3000 \mathrm{ppm}$ as the 
LOAEL and $1000 \mathrm{ppm}(67.9 \mathrm{mg} / \mathrm{kg}$ bw/day) as the NOAEL based on the decrease in spermatocytes. This value was used as a PoD for risk characterization.

\subsubsection{Systemic Exposure Dose (SED) Calculation Based on an External Approach}

\section{- $\quad$ Skin penetration}

Dermal absorption was determined using an in vitro study with $6 \% \mathrm{BP}-3$ that had been considered in the previous SCCP Opinion [15]. Due to some shortcomings in this study, the SCCS applied an additional $2 \times$ SD (standard deviation) to the reported mean dermal absorption value. A dermal absorption of $9.9 \%$ was used for the calculation of SED. For other cosmetic products, a dermal absorption of $8 \%$ based on the results of the study performed with $2 \%$ BP-3 was used [2].

- Calculation of the SED

The calculation of the SED following application of a whole-body UV-cream containing up to $6 \% \mathrm{BP}-3$, the intended level of use requested by the cosmetic industry, was estimated at $1.78 \mathrm{mg} / \mathrm{kg}$ bw/day, as detailed in Table 1.

Table 1. Systemic exposure by dermal route from whole-body UV-cream containing up to $6 \%$ BP-3 (adapted from SCCS opinion [2]).

\begin{tabular}{|c|c|c|c|}
\hline Description & Parameter & Value & Unit \\
\hline Amount of sunscreen product used & $\mathrm{A}$ & 18 & g/day \\
\hline Concentration of BP-3 & $\mathrm{C}$ & 6 & $\%$ \\
\hline Dermal absorption & $\mathrm{DA}_{\mathrm{p}}$ & 9.9 & $\%$ \\
\hline Human body weight & $\mathrm{Bw}$ & 60 & $\mathrm{~kg}$ \\
\hline Systemic exposure dose (SED) & $\mathrm{A} \times 1000 \mathrm{mg} / \mathrm{kg} \times \mathrm{C} / 100 \times \mathrm{DA}_{\mathrm{p}} / 100 / \mathrm{bw}$ & 1.78 & $\mathrm{mg} / \mathrm{kg}$ bw/day \\
\hline
\end{tabular}

Exposure via other types of cosmetic products (UV or non-UV) by dermal, inhalation or oral routes was also considered by SCCS (see Table 2 below).

Table 2. Calculation of margin of safety for different products containing BP-3 (adapted from SCCS opinion [2]).

\begin{tabular}{|c|c|c|c|c|c|}
\hline $\begin{array}{c}\text { Product } \\
\text { Categories }\end{array}$ & Conc. & Surface & Total * Systemic Exposure Dose (SED) $\mathrm{mg} / \mathrm{kg} \mathrm{bw/d}$ & NOAEL ${ }^{* *}$ & MoS \\
\hline UV cream & $6 \%$ & whole body & 1.78 & 67.9 & 38 \\
\hline UV aerosolized spray & $6 \%$ & whole body & 1.89 & 67.9 & 36 \\
\hline UV pump spray & $6 \%$ & whole body & 1.78 & 67.9 & 38 \\
\hline UV face cream & $6 \%$ & face & 0.15 & 67.9 & 447 \\
\hline UV hand cream & $6 \%$ & hand & 0.21 & 67.9 & 317 \\
\hline Non-UV *** & $0.50 \%$ & whole body & 0.12 & 67.9 & 585 \\
\hline Lipstick & $6 \%$ & lips & 0.05 & 67.9 & 1257 \\
\hline
\end{tabular}

$* * *$ to protect cosmetic formulations.

\subsubsection{MoS Calculation}

Because of the evidence for rapid and almost complete absorption of BP-3 from the oral route, the SCCS did not apply any adjustment for bioavailability to this NOAEL value. Details of the calculation of systemic exposure dose (SED) are presented in the Tables in Annex 2 of the SCCS opinion. The calculation of MoS for different product types ranged between 1257 for lipstick and 36-38 for UV aerosolized spray and cream. MOS for hand cream and face cream were 317 and 447, respectively (see Table 2). 
A margin of safety (MoS) of 38 was estimated for the use of BP-3 at a concentration of $6 \%$ as a UV-filter in sunscreens for the whole-body application (in the form of cream/lotion or pump spray), 36 for sunscreen propellant spray, and 447 for the face, 317 for the hand and 1257 for lipstick application. The MoS was estimated at 585 for the use of BP-3 at $0.5 \%$ to protect cosmetic formulations against sunlight. As mentioned before, a default value of $100(10 \times 10)$ accounting for inter- and intraspecies differences is generally acceptable, and as an MoS of at least 100 therefore indicates that a cosmetic ingredient is safe for use [3], the SCCS assessment of BP-3 concluded that:

- The use of BP-3 as a UV-filter up to a maximum concentration of $6 \%$ in sunscreen products is not safe for the consumer with the exception of face cream, hand cream, and lipsticks

- The use of BP-3 up to $0.5 \%$ in cosmetic products to protect the cosmetic formulation is safe for the consumer.

\subsection{Risk Assessment Based on Internal Approach}

\subsubsection{Provisional HBM-GV Derivation Using the Urinary Mass Balance Approach}

In this study, the same POD of $67.9 \mathrm{mg} / \mathrm{kg}$ bw/day as selected by the SCCS [2] was used as a starting point in the derivation of a provisional HBM-GV that was used to calculate the risk based on the biomonitoring data. In accordance with the ECHA guidance R.8, assessment factors (AFs) for allometric scaling, remaining interspecies differences, and intraspecies differences were applied [6]. The guidance additionally prescribes an AF for exposure duration extrapolation, where appropriate. This AF is generally applied to account for differences in exposure between the experimental toxicity study and real-life situation. However, as in the study from Nakamura et al. (2015) [19], animals were exposed during gestation, which corresponds to a sensitive window of exposure, and no other AF were considered necessary to extrapolate from sub-acute to chronic exposure duration. In view of this, an overall AF of 100 was constituted from the following default AFs:

- $\quad$ Allometric scaling (rat to human): 4

- Remaining interspecies differences: 2.5

- Intraspecies differences: 10

- Duration extrapolation: 1

- Overall AF: $\quad 4 * 2.5 * 10 * 1=100$

The Fue was obtained from two human experimental exposure studies [20,21]. Hayden et al. (1997) reported BP-3 levels in urine to be $1-2 \%$ of the initial dose $10 \mathrm{~h}$ after dermal application to nine healthy adult volunteers [20]. Sarveiya et al. (2004) similarly reported up to $1 \%$ BP-3 of the initial dose dermally applied to three female volunteers and measured

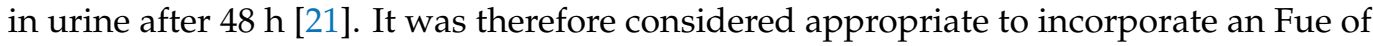
$0.01(1 \%)$ as a conservative value.

The HBM4EU default average daily creatinine excretion was incorporated in the derivation of the provisional HBM-GV. The HBM4EU default creatinine value is based on the calculation according to Aylward et al. (2009) [22], and amounts to an average total amount of creatinine excreted of $1.4 \mathrm{~g} / \mathrm{L}$ per day for both sexes combined. Adjusted to the default body weight of $70 \mathrm{~kg}$, as defined by ECHA R.8 [6] and followed by HBM4EU, this amounted to an average creatinine excretion rate of $0.02 \mathrm{~g} / \mathrm{kg}$ bw/day. Table 3 presents an overview of the information and parameters incorporated in the provisional HBMGV calculation.

Application of the overall AF to the animal PoD in Equation (7) provided the TRV:

$$
\mathrm{TRV}=\frac{67.9}{100}=0.68 \mathrm{mg} / \mathrm{kg} \mathrm{bw} / \text { day }
$$

Incorporating the TRV and remaining parameters (Table 3) in Equation (8) provided the provisional HBM-GV: 
provisional HBM $-\mathrm{GV}($ GenPop $)=\frac{0.68 * 0.01}{0.02}=0.34 \mathrm{mg} / \mathrm{g}$ creatine $=340 \mu \mathrm{g} / \mathrm{g}$ creatinine

Table 3. Overview of parameter values incorporated in the provisional HBM-GV calculation, with sources.

\begin{tabular}{ccc}
\hline Parameter & Value & Source \\
\hline Animal PoD & $\mathrm{NOAEL}=67.9 \mathrm{mg} / \mathrm{kg} \mathrm{bw} /$ day & SCCS opinion (2021) [2] \\
\hline Overall AF & $\mathrm{AF}=100$ & ECHA R.8 guidance, SCCS opinion [6] \\
\hline Fue & $1 \%$ or 0.01 & Hayden et al. (1997); Sarveiya et al. (2004) [20,21] \\
\hline $24 \mathrm{~h}$ creatinine & $0.02 \mathrm{~g} / \mathrm{kg} \mathrm{bw} /$ day & HBM4EU default from Aylward et al. (2009) [22] \\
\hline
\end{tabular}

\subsubsection{Systemic Exposure Dose Calculation Based on an Internal Approach}

The internal exposure was assessed with a meta-analysis of the biomonitoring data. Screening and selection resulted in 17 articles with biomonitoring data on BP-3 in the European cohorts. After application of the exclusion criteria and selection of the studies that used sufficient numbers of samples $(>120), 8$ studies were selected. Out of these, only 3 studies that had used creatinine correction were considered in the meta-analysis [23-25]. Table 4 presents the cohort characteristics and study-specific descriptive statistics of creatininecorrected concentrations of BP-3 and BP-1. Frederiksen et al. (2013) [25] reported BP-3 measurements in first morning urine samples of mother-child pairs in Denmark. Dewalque et al. (2014) [24] reported BP-3 measurements in spot urine samples from the general population in Belgium. Adoamnei et al. (2018) [23] reported BP-3 and BP-1 measurements in first morning urine samples of male students in Spain. However, this study did not report maximum measured concentrations.

Table 4. Cohort characteristics and descriptive statistics reported by the final three studies included in the meta-analysis of exposure. All concentrations (P50, P75, P95, max) are creatinine-corrected and thus expressed as $\mu \mathrm{g} / \mathrm{g}$ creatinine. Concentrations $>$ provisional HBM-GV in bold.

\begin{tabular}{|c|c|c|c|c|c|c|c|c|c|c|}
\hline Study & Sampling Period & N/Sex & $\begin{array}{c}\text { Age } \\
\text { Range }\end{array}$ & Sample & Chemical & $\begin{array}{c}\text { LOD } \\
(\%>\text { LOD })\end{array}$ & P50 & P75 & $\begin{array}{c}\text { P95 } \\
\text { (RCR) }\end{array}$ & Max \\
\hline \multirow[t]{2}{*}{$\begin{array}{c}\text { Frederiksen et al. } \\
(2013) \\
\text { Denmark }\end{array}$} & $\begin{array}{l}\text { September 2011-December } \\
2011\end{array}$ & $143 \mathrm{M} / \mathrm{F}$ & $6-11$ & Morning & BP-3 & $\begin{array}{c}0.07 \\
(97.0 \%)\end{array}$ & 2.00 & 6.30 & $33.00(0.1)$ & 408.00 \\
\hline & & $154 \mathrm{~F}$ & $31-52$ & Morning & BP-3 & $\begin{array}{c}0.07 \\
(98.0 \%)\end{array}$ & 4.40 & 15.00 & 392.00 (1.15) & 2139.00 \\
\hline \multirow[t]{2}{*}{$\begin{array}{c}\text { Dewalque et al. } \\
(2014) \\
\text { Belgium }\end{array}$} & January 2013-April 2013 & $123 \mathrm{M}$ & $2-75$ & Spot & BP-3 & $\begin{array}{c}0.20 \\
(82.1 \%)\end{array}$ & 0.60 & 2.00 & $28.80(0.08)$ & 414.20 \\
\hline & & $138 \mathrm{~F}$ & $1-85$ & Spot & BP-3 & $\begin{array}{c}0.20 \\
(83.3 \%)\end{array}$ & 1.30 & 4.40 & $33.30(0.1)$ & 141.30 \\
\hline \multirow[t]{2}{*}{$\begin{array}{l}\text { Adoamnei et al. } \\
\text { (2018) } \\
\text { Spain }\end{array}$} & $\begin{array}{l}\text { October 2010-November } \\
2011\end{array}$ & $215 \mathrm{M}$ & $18-23$ & Morning & BP-3 & $\begin{array}{c}0.20 \\
(65.6 \%)\end{array}$ & 0.96 & 4.60 & $16.30(0.05)$ & NA \\
\hline & & & & & BP-1 & $\begin{array}{c}0.10 \\
(97.2 \%)\end{array}$ & 1.60 & 3.10 & $9.90(0.03)$ & NA \\
\hline
\end{tabular}

N: sample size, M: male; F: female; age range: minimum-maximum age in years; LOD: limit of detection; NA: not available.

The TC of BP-3 exposure (based on median values across the studies) ranged from 0.60 to $4.40 \mu \mathrm{g} / \mathrm{g}$ creatinine, with a median of $1.30 \mu \mathrm{g} / \mathrm{g}$ creatinine. The RWC BP-3 exposure (based on P95 values across the studies) varied between 16.30 and $392.00 \mu \mathrm{g} / \mathrm{g}$ creatinine, with a median of $33.00 \mu \mathrm{g} / \mathrm{g}$ creatinine. 


\subsubsection{Risk Characterization Ratio (RCR) Calculation}

Comparing the TC exposure range ( 0.60 to $4.40 \mu \mathrm{g} / \mathrm{g}$ creatinine) and the RWC exposure range (16.30 to $392.00 \mu \mathrm{g} / \mathrm{g}$ creatinine) with the provisional HBM-GV (340 $\mu \mathrm{g} / \mathrm{g}$ creatinine) in Equations (3) and (4) provided the following RCRs:

$$
\begin{gathered}
\operatorname{RCR}(\mathrm{TC})=\frac{0.60 \text { to } 4.40}{340}=0.002 \text { to } 0.01=\mathrm{RCR}<1 \\
\operatorname{RCR}(\mathrm{RWC})=\frac{16.30 \text { to } 392.00}{340}=0.05 \text { to } 1.15=\mathrm{RCR}>1
\end{gathered}
$$

For typical case exposure, the RCR was below 1, so median HBM results did not exceed the orientation value. However, for a reasonable worst-case exposure, the RCR slightly exceeded 1 . Table 4 shows the HBM values exceeding the provisional HBM-GV in bold, as well as the RCR values at the RWC/P95 value. The P95 value reported by Frederiksen et al. (2013) [25] for Danish females exceeded the provisional HBM-GV. The maximum values for female participants and children in Frederiksen et al. (2013) [25] and for male participants in Dewalque et al. (2014) [24] exceeded the provisional HBM-GV.

In summary, HBM values did not exceed the provisional HBM-GV for a typical exposure scenario and were therefore within safe limits. They did, however, exceed the provisional HBM-GV slightly in the reasonable worst-case exposure scenario, indicating potential risk to the highly exposed part of the population.

\section{Discussion}

In most chemical risk assessment frameworks, the default approach is to assess external intake from different sources of exposure, as well as via different routes of exposure, which are often assessed separately. In the context of cosmetics risk assessment, dermal exposure is calculated using the estimated amount of a product applied, retention factor of the product, and skin penetration value of the chemical. This approach includes various uncertainties and often overestimates the real uptake because default, conservative estimates are used, e.g., for the amount of product used. At the same time, actual (real-life) exposure may be underestimated by not taking into account that exposure to a chemical substance may occur from different sources that may fall under different legislative frameworks [4]. The use of HBM studies in chemical risk assessment has not yet become common practice, and its value in risk assessment remains largely unexplored. Within the HBM4EU project, it is the aim to increase the quality of HBM data and provide policymakers with tools to use these data in risk assessment.

BP-3 is mainly used in cosmetics, and a recent safety evaluation has been performed by the SCCS, instigated by concerns on the ED properties of BP-3. As is usual practice, the exposure estimate in the opinion was based on the use patterns of sunscreen and other cosmetic products (SCCS/1625/20) and dermal absorption of BP-3. No risk assessment for exposure of the European population to BP-3 using HBM data has been performed to date. This study used BP-3 as an example to investigate the usefulness of HBM in risk assessment, and for informing decision-making throughout the risk assessment process-in particular to address the additional research questions.

This study has compared two parallel risk assessment approaches-one based on the external exposure (the SCCS approach), and the other on internal exposure data from three different countries in Europe (the HBM approach). The results showed a remarkably similar overall conclusion in that the highly exposed individuals would be at a (slightly) increased risk from the intended levels of BP-3 use in certain product categories.

It needs to be noted that the internal dose approach used in HBM includes all sources of exposure, including from cosmetics. Therefore, although the estimated RWC is only slightly above 1, it does not truly reflect the risk to consumers from cosmetics only. The RWC was based on the P95, which could reflect exposure to BP-3 via cosmetic products, whereas the RTC, which is based on the mean, could be more representative of the background exposure to BP-3 either via cosmetic products other than sun-care products or via other consumer 
products. BP-3 is indeed also used in consumer products to protect formulations from degradation by the sun. Unfortunately, in the biomonitoring studies that have measured BP-3 in Europe, there is no product use data to show where this exposure comes from. In the study from Zamoiski et al. (2016) [26], the authors observed based on urinary concentrations of BP-3 measured in NHANES 2003-2006 and 2009-2012 that BP-3 was positively associated with self-reported frequency of sunscreen use and that concentrations of BP-3 in the more frequent users were $116.8 \mu \mathrm{g} / \mathrm{g}$ creatinine, which is above the P95 reported in Belgium and Spain $[23,24]$ but lower than the Danish values [25]. It was rather surprising to see the highest BP-3 exposure in a study with a sampling period only in the fall in a northern country [25]. A similarly unexpected outcome was seen in a recent study performed in Israel, where sunscreen products are widely used, that reported relatively low internal exposure [27]. Thus, more information on product use would be valuable to gain more insight on the products contributing to BP-3 exposure. Moreover, the study populations were relatively small, which adds uncertainty in the extrapolation to the entire European population. Vogel et al. (2019) [28], recommended samples of at least 72 to 120 individuals to be able to define reference values for the general population, which is in line with the 3 biomonitoring studies we have included in our assessment.

In contrast, the external approach, as currently used by the SCCS, is conservative as it considers that the concentration is at the maximum requested level for all the cosmetic products formulated with BP-3. In addition, for the aggregated exposure scenario, the SCCS does not take into account market penetration and assumes that all the products in the product category concerned contain BP-3. Neither of these assumptions are realistic and they make the SCCS approach conservative. Where data are available, the SCCS methodology incorporates a refinement in terms of the use of a probabilistic approach to exposure assessment to take into account the distribution of values for exposure parameters, such as concentration in the products, amounts of the products used, etc. However, this approach is subject to the availability of data on these distributions and therefore may not be practicable in all cases.

There are certain differences between the external and internal dose approaches that also warrant further attention.

Both external/internal exposure-based approaches have certain advantages and disadvantages that are illustrated in Table 5.

HBM data provide data on exposure from all routes and sources, which can be an advantage when there is a concern over aggregated exposure. In such situations, the availability of actual data is a distinct advantage because aggregate exposure measurements often suffer from high levels of uncertainty. However, to answer questions on specific product contributions, additional product-specific exposure estimations will remain a necessity. Based on the available information, it is difficult to have a clear understanding of the exposure profile to BP-3 and the contribution of different sources of exposure. BP-3 is used as a UV-filter not only in cosmetic sun-care products, but also in other consumer products such as washing and cleaning products, anti-freeze products, biocides (e.g., disinfectants, pest control products), and printing inks in food contact materials [7]. Intervention studies have shown that by avoiding the use of cosmetic products containing BP-3, internal exposure can be significantly reduced, which indicates that cosmetics are an important source of exposure to BP-3 [29,30].

Another consideration for biomonitoring studies is that they are by nature retrospective. They can only be used for retrospective risk management by showing the actual exposure under a certain regulatory regime, but not to predict exposure before placing a new product on the market, or authorizing a new ingredient. HBM data can, however, be used to assess the impact of new regulatory measures by measuring time trends. In fact, the HBM data used here were from before the previous decrease in maximum concentration of BP-3 in cosmetic products that went into effect in 2017. An update of this risk assessment will be performed within HBM4EU based on measurements from 2020, the outcome of which will give a better understanding of the current situation. 
Table 5. Differences between current SCCS approach and HBM approach for risk assessment.

\begin{tabular}{|c|c|c|}
\hline & Current SCCS Approach & HBM Approach \\
\hline Dose estimation & Modeled/estimated & $\begin{array}{l}\text { Measured, real-world } \\
\text { conditions }\end{array}$ \\
\hline Exposure pathways & Dermal exposure & $\begin{array}{c}\text { Provides data on total } \\
\text { exposure from all exposure } \\
\text { pathways }\end{array}$ \\
\hline Temporality & $\begin{array}{l}\text { No time lag; can be used in a } \\
\text { predictive approach }\end{array}$ & $\begin{array}{c}\text { Time lag between exposure } \\
\text { estimate and risk assessment; } \\
\text { only retrospective; cannot be } \\
\text { used in a prospective } \\
\text { approach }\end{array}$ \\
\hline Product specificity & $\begin{array}{l}\text { Calculations per product type, } \\
\text { combining several } \\
\text { conservative parameters in a } \\
\text { deterministic assessment may } \\
\text { lead to overestimation }\end{array}$ & $\begin{array}{l}\text { No product-specific data: } \\
\text { aggregate exposure modeling } \\
\text { needed to identify relative } \\
\text { contribution of a product to } \\
\text { the overall exposure }\end{array}$ \\
\hline $\begin{array}{l}\text { Consideration for } \\
\text { toxicokinetic aspects }\end{array}$ & $\begin{array}{l}\text { Generally uses in vitro studies } \\
\text { for dermal absorption and } \\
\text { historic animal studies for } \\
\text { PoD and applies an AF to } \\
\text { correct for animal-human } \\
\text { differences }\end{array}$ & $\begin{array}{l}\text { Considers biotransformation } \\
\text { and elimination of the } \\
\text { substance in humans, but } \\
\text { requires appropriate timing of } \\
\text { sampling }\end{array}$ \\
\hline $\begin{array}{c}\text { Conclusion of risk } \\
\text { assessment for BP-3 }\end{array}$ & $\begin{array}{l}\text { Exposure at the intended use } \\
\text { levels exceeds safe dose for } \\
\text { whole-body cream and spray } \\
\text { but not face or hand cream }\end{array}$ & $\begin{array}{l}\text { Exposure exceeds safe dose in } \\
\text { highly exposed individuals }\end{array}$ \\
\hline
\end{tabular}

Where there is a special interest in a specific, vulnerable groups within the population, such as children or pregnant woman, HBM data have the advantage in terms of providing an insight into the exposure of separate groups. This is equally possible through modeling of external exposure, but only if the required use data are available for these groups.

The SCCS guidance for the testing of cosmetic ingredients and their safety evaluation [3] noted that HBM data should be used to support risk assessment and risk management. For example, HBM can serve to evaluate whether the dose estimation model over- or under-estimates the real exposure. Especially in light of the prohibition of in vivo animal studies on cosmetic substances, HBM offers a means to inform risk assessment by providing real-life in vivo information from human studies, without the need for interspecies extrapolation or the limitation of a small number of subjects often used in human volunteer studies. Indeed, HBM data were also noted in the SCCS opinion on BP-3 (SCCS/1625/20), but not used as such in modeling the exposure, or supporting the safety assessment.

\section{Conclusions}

HBM has the potential to be a useful tool for regulatory risk assessment as it provides actual exposure levels, but it is currently rarely applied in regulatory practice. Within the HBM4EU project, it was proposed to collect and create successful examples on the use of HBM data in chemical risk assessment. The experience from these cases could be used as a basis for developing harmonized guidance on the use of biomonitoring data in risk assessment, which was indicated as critical to the use of HBM. The aim of this work was to compare an HBM case study on BP-3 with a 'traditional' risk assessment. The results have shown that both the current SCCS approach and the HBM approach have their own advantages for risk assessment of cosmetic products. In the case of BP-3, both approaches indicated similar levels of risk. The comparison also indicated that HBM data can be useful in supporting risk assessment by providing real-life data on exposure, and may also play an 
important role in post-approval assessment studies on exposure trends. However, before being adopted for use on a regular basis in regulatory risk assessments, more efforts are needed to better harmonize HBM surveys, and to obtain robust data that are representative of the exposure of the European population. This study has also highlighted the need for the development of a standardized framework for incorporation of HBM data in the current risk assessment of cosmetic products.

Author Contributions: Conceptualization, C.R., M.W. and M.M.; methodology, C.R., M.W., W.B., J.W. and T.B.; validation Q.C. and T.B.; investigation, C.R., M.W., W.B., J.W. and Q.C.; writing-original draft preparation, C.R., M.M. and M.W.; writing-review and editing, Q.C. and T.B.; Q.C. and C.R. are members of the SCCS. C.R., M.M., T.B., M.W., W.B. and J.W. are partners of the HBM4EU project. All authors have read and agreed to the published version of the manuscript.

Funding: Some of the authors (Christophe Rousselle, Matthieu Meslin, Tamar Berman, Marjolijn Woutersen, Wieneke Bil and Jenna Wildeman) received funding as part of the European Union's Horizon 2020 research and innovation program (grant agreement No 733032, HBM4EU), and also received co-funding from their respective organizations.

Institutional Review Board Statement: Not applicable.

Informed Consent Statement: Not applicable.

Data Availability Statement: Not applicable.

Acknowledgments: The authors are grateful to Members of the SCCS and Partners of HBM4EU project whose work contributed to this article.

Conflicts of Interest: The authors declare no conflict of interest. The funders had no role in the design of the study; in the collection, analyses, or interpretation of data; in the writing of the manuscript, or in the decision to publish the results.

\section{Abbreviations}

AF: assessment factor, ALT: albumin transferase, BMD: benchmark dose, BP-3: benzophenone-3, BW: body weight, C: concentration, CPR: Cosmetic Product Regulation, CLP: classification, labeling, and packaging, ED: endocrine disrupting, $\mathrm{E}_{\mathrm{dermal}}$ : dermal exposure, EU: European Union, $\mathrm{f}_{\text {ret }}$ : retention factor, $\mathrm{F}_{\mathrm{ue}}$ : steady-state fraction of urinary excretion, HBM: human biomonitoring, HBM4EU: European Human Biomonitoring Initiative, HBM-GV: human biomonitoring guidance value, LOAEL: lowest observed adverse effect level, LOD: limit of detection, LOQ: limit of quantification, MoS: margin of safety, NOAEL: no observed adverse effect level, PND: post-natal day, PoD: point of departure, PoDsys: systemic PoD, q $\mathrm{q}_{\mathrm{x}}$ : quantity applied per day, RCR: risk characterization ratio, RWC: reasonable worst-case, SCCS: Scientific Committee on Consumer Safety, SD: standard deviation, SED: systemic exposure dose, TC: typical case, TRV: toxicological reference value.

\section{References}

1. Report from the Commission to the European Parliament and the Council Review of Regulation (EC) No 1223/2009 of the European Parliament and of the Council on Cosmetic Products with Regard to Substances with Endocrine-Disrupting Properties. Available online: https://eur-lex.europa.eu/legal-content/EN/TXT/PDF/?uri=CELEX:52018DC0739 (accessed on 16 October 2021).

2. Scientific Committee on Consumer Safety (SCCS). Request for a Scientific Opinion on Benzophenone-3 (CAS No 131-57-7, EC No 205-031-5). Available online: https:/ / ec.europa.eu/health/sites/default/files/scientific_committees/consumer_safety/docs/ sccs2016_q_038.pdf (accessed on 16 October 2021).

3. Scientific Committee on Consumer Safety (SCCS). The SCCS Notes of Guidance for the Testing of Cosmetic Ingredients and Their Safety Evaluation 11th Revision, Adopted in March 2021. Available online: https:/ / ec.europa.eu/health/sites/default/files/ scientific_committees/consumer_safety/docs/sccs_o_250.pdf (accessed on 16 October 2021).

4. Louro, H.; Heinälä, M.; Bessems, J.; Buekers, J.; Vermeire, T.; Woutersen, M.; van Engelen, J.; Borges, T.; Rousselle, C.; Ougier, E.; et al. Human biomonitoring in health risk assessment in Europe: Current practices and recommendations for the future. Int. J. Hyg. Environ. Health 2019, 222, 727-737. [CrossRef] [PubMed]

5. HBM4EU-Science and Policy for a Healthy Future. Available online: https://www.hbm4eu.eu/ (accessed on 16 October 2021). 
6. European Chemical Agency (ECHA). Guidance on Information Requirements and Chemical Safety Assessment. Chapter R.8: Characterisation of Dose [Concentration]-Response for Human Health. Available online: https:/ / echa.europa.eu/documents/10 162/13632/information_requirements_r8_en.pdf/e153243a-03f0-44c5-8808-88af66223258 (accessed on 16 October 2021).

7. European Chemical Agency (ECHA). Substance Information Benzophenone 3. Available online: https://echa.europa.eu/de/ substance-information/-/substanceinfo/100.003.943 (accessed on 16 October 2021).

8. Scientific Committee on Consumer Safety (SCCS). Basic Criteria for the In Vitro Assessment of Dermal Absorption of Cosmetic Ingredients, Adopted June 2010. Available online: https:/ / ec.europa.eu/health/scientific_committees/consumer_safety/docs/ sccs_s_002.pdf (accessed on 5 January 2022).

9. Apel, P.; Rousselle, C.; Lange, R.; Sissoko, F.; Kolossa-Gehring, M.; Ougier, E. Human biomonitoring initiative (HBM4EU)-Strategy to derive human biomonitoring guidance values (HBM-GVs) for health risk assessment. Int. J. Hyg. Environ. Health 2020, 230, 113622. [CrossRef] [PubMed]

10. Angerer, J.; Aylward, L.L.; Hays, S.M.; Heinzow, B.; Wilhelm, M. Human biomonitoring assessment values: Approaches and data requirements. Int. J. Hyg. Environ. Health 2011, 214, 348-360. [CrossRef] [PubMed]

11. Frederiksen, H.; Nielsen, O.; Skakkebaek, N.E.; Juul, A.; Andersson, A.-M. UV Filters Analyzed by Isotope Diluted TurboFlowLC-MS/MS in Urine from Danish Children and Adolescents. Int. J. Hyg. Environ. Health 2017, 220, 244-253. [CrossRef] [PubMed]

12. Knutsen, H.K.; Alexander, J. Risk to human health related to the presence of perfluorooctane sulfonic acid and perfluorooctanoic acid in food. EFSA J. 2018, 16, 5194.

13. Scientific Committee on Cosmetic Products and Non-Food Products Intended for Consumers (SCCNFP). Opinion on the Evaluation of Potentially Estrogenic Effects of UV-Filters Adopted by the SCCNFP during the 17th Plenary Meeting of 12 June 2001. Available online: https:/ / ec.europa.eu/health/scientific_committees/consumer_safety/opinions/sccnfp_opinions_97_0 4/sccp_out145_en.htm (accessed on 5 January 2022).

14. Scientific Committee on Consumer Products (SCCP). Opinion on Benzophenone-3. (COLIPA N ${ }^{\circ}$ S38), SCCS/1069/06, Adopted 19 December 2006. Available online: https:/ / ec.europa.eu/health/ph_risk/committees/04_sccp/docs/sccp_o_078.pdf (accessed on 5 January 2022).

15. Scientific Committee on Consumer Products (SCCP). Opinion on Benzophenone-3. (COLIPA N ${ }^{\circ}$ S38), SCCS/1201/08, Adopted 16 December 2008. Available online: https:/ / ec.europa.eu/health/ph_risk/committees/04_sccp/docs/sccp_o_159.pdf (accessed on 5 January 2022).

16. Regulation (EC) No 1272/2008 of the European Parliament and of the Council of 16 December 2008 on Classification, Labelling and Packaging of Substances and Mixtures, Amending and Repealing Directives 67/548/EEC and 1999/45/EC, and Amending Regulation (EC) No 1907/2006. Available online: https:/ / eur-lex.europa.eu/legal-content/en/TXT/?uri=CELEX\%3A32008R127 2 (accessed on 16 October 2021).

17. Ghazipura, M.; McGowan, R.; Arslan, A.; Hossain, T. Exposure to benzo-phenone-3 and reproductive toxicity: A systematic review of human and animal studies. Reprod. Toxicol. 2017, 7, 175-183. [CrossRef] [PubMed]

18. Kim, S.; Choi, K. Occurrences, toxicities, and ecological risks of benzophenone-3, a common component of organic sunscreen products: A mini-review. Environ. Int. 2014, 70, 143-157. [CrossRef] [PubMed]

19. Nakamura, N.; Inselman, A.; White, G.A.; Chang, C.-W.; Trbojevich, R.A.; Sephr, E.; Voris, K.L.; Patton, R.E.; Bryant, M.S.; Harrouk, W.; et al. Effects of maternal and lactational exposure to 2-hydroxy-4-methoxybenzone on development and reproductive organs in male and female rat offspring. Birth Defects Res. Part B Dev. Reprod. Toxicol. 2015, 104, 35-51. [CrossRef] [PubMed]

20. Hayden, C.; Roberts, M.; Benson, H.A. Systemic absorption of sunscreen after topical application. Lancet 1997, 350, 863-864 [CrossRef]

21. Sarveiya, V.; Risk, S.; Benson, H.A. Liquid chromatographic assay for common sunscreen agents: Application to in vivo assessment of skin penetration and systemic absorption in human volunteers. J. Chromatogr. B 2004, 803, 225-231. [CrossRef] [PubMed]

22. Aylward, L.L.; Hays, S.M.; Gagné, M.; Krishnan, K. Derivation of Biomonitoring Equivalents for di(2-ethylhexyl)phthalate (CAS No. 117-81-7). Regul. Toxicol. Pharmacol. 2009, 55, 249-258. [CrossRef] [PubMed]

23. Adoamnei, E.; Mendiola, J.; Moñino-García, M.; Vela-Soria, F.; Iribarne-Durán, L.M.; Fernández, M.F.; Olea, N.; Jørgensen, N.; Swan, S.; Torres-Cantero, A.M. Urinary concentrations of benzophenone-type ultra violet light filters and reproductive parameters in young men. Int. J. Hyg. Environ. Health 2018, 221, 531-540. [CrossRef] [PubMed]

24. Dewalque, L.; Pirard, C.; Charlier, C. Measurement of Urinary Biomarkers of Parabens, Benzophenone-3, and Phthalates in a Belgian Population. BioMed Res. Int. 2014, 2014, 649314. [CrossRef] [PubMed]

25. Frederiksen, H.; Nielsen, J.K.S.; Mørck, T.A.; Hansen, P.W.; Jensen, J.F.; Nielsen, O.; Andersson, A.-M.; Knudsen, L.E. Urinary excretion of phthalate metabolites, phenols and parabens in rural and urban Danish mother-child pairs. Int. J. Hyg. Environ. Health 2013, 216, 772-783. [CrossRef] [PubMed]

26. Zamoiski, R.D.; Cahoon, E.K.; Freedman, D.M.; Linet, M.S. Self-reported sunscreen use and urinary benzophenone-3 concentrations in the United States: NHANES 2003-2006 and 2009-2012. Environ. Res. 2015, 142, 563-567. [CrossRef] [PubMed]

27. Machtinger, R.; Berman, T.; Adir, M.; Mansur, A.; Baccarelli, A.A.; Racowsky, C.; Calafat, A.M.; Hauser, R.; Nahum, R. Urinary concentrations of phthalate metabolites, bisphenols and personal care product chemical biomarkers in pregnant women in Israel. Environ. Int. 2018, 116, 319-325. [CrossRef] [PubMed] 
28. Vogel, N.; Conrad, A.; Apel, P.; Rucic, E.; Kolossa-Gehring, M. Human biomonitoring reference values: Differences and similarities between approaches for identifying unusually high exposure of pollutants in humans. Int. J. Hyg. Environ. Health 2018, 222, 30-33. [CrossRef] [PubMed]

29. Harley, K.G.; Kogut, K.; Madrigal, D.S.; Cardenas, M.; Vera, I.A.; Meza-Alfaro, G.; She, J.; Gavin, Q.; Zahedi, R.; Bradman, A.; et al. Reducing Phthalate, Paraben, and Phenol Exposure from Personal Care Products in Adolescent Girls: Findings from the HERMOSA Intervention Study. Environ. Health Perspect. 2016, 124, 1600-1607. [CrossRef] [PubMed]

30. Dodson, R.E.; Boronow, K.E.; Susmann, H.; Udesky, J.O.; Rodgers, K.M.; Weller, D.; Woudneh, M.; Brody, J.G.; Rudel, R.A. Consumer behavior and exposure to parabens, bisphenols, triclosan, dichlorophenols, and benzophenone-3: Results from a crowdsourced biomonitoring study. Int. J. Hyg. Environ. Health 2020, 230, 113624. [CrossRef] [PubMed] 